\title{
PENERAPAN LATIHAN HOLLOW SPRINT DAN PICKUP SPRINT DALAM PENINGKATAN KECEPATAN LARI
}

\author{
MUHAMMAD FAZ ARDIANA \\ UNIVERSITAS GARUT
}

afezici@gmail.com

\begin{abstract}
Abstrak
Kecepatan merupakan salah satu aspek komponen fisik yang sangat berpengaruh dalam olahraga. Atlet yang memiliki kecepatan akan cepat mendapatkan apa yang menjadi targetnya. Hubungan kecepatan dengan prestasi dalam olahraga memiliki hubungan yang positif untuk menentukan hasil pencapaian yang optimal. Dalam hal ini peneliti ingin mengetahui pengaruh metode latihan yang diberikan kepada atlet dalam upaya meningkatkan kemampuan kecepatan atlet sepakbola, apakah ada pengaruh yang signifikan dari metode hollow sprints dan pickup/acceleration sprints dan manakah yang lebih baik diantara kedua metode latihan tersebut. Metode yang digunakan dalam penelitian ini adalah metode eksperimen. Populasi dalam penelitian ini adalah siswa SSB Pamong Praja Kabupaten Garut, sedangkan sampel yang digunakan terdiri dari 20 orang siswa SSB Pamong Praja Kabupaten Garut. Penelitian ini dilakukan selama 7 minggu dengan frekuensi latihan 3 kali dalam seminggu. Berdasarkan pengolahan dan analisis data yang diperoleh, maka hasil penelitian adalah terdapat peningkatan yang signifikan dari metode hollow sprints dan metode pickup/acceleration sprints terhadap kecepatan pemain sepakbola. Jika dibandingkan terdapat perbedaan pengaruh yang signifikan dari metode hollow sprints dan metode pickup/acceleration sprints terhadap kecepatan pemain sepakbola. Oleh karena itu penulis mengambil kesimpulan bahwa latihan kecepatan menggunakan metode pickup/acceleration sprints lebih signifikan dibandingkan metode hollow sprints dilihat dari uji t.
\end{abstract}

Kata Kunci : hollow sprints, kecepatan, metode latihan dan pickup/acceleration sprints.

Abstract

Speed is one aspect of the physical component that is very influential in sports. Athletes who have speed will quickly get what they target. The relationship between speed and performance in sports has a positive relationship to determine the results achieved. Usually athletes who have good speed will get optimal performance. In this case the researcher wants to know the effect of the training method given to athletes in an effort to increase the athlete's speed of ability, whether there is a significant effect of the hollow sprints method and pickup / acceleration sprints and which is better between the two training methods. The method used in this research is the experimental method. The population in this study were students of the SSB Pamong Praja Garut Regency, while the sample used consisted of 20 students of the SSB Pamong Praja Garut Regency. This research was conducted for 7 weeks with a frequency of exercise 3 times a week. Based on the processing and analysis of the data obtained, the results of the study show that there is a significant increase in the hollow sprints method and the pickup / acceleration sprints method on the speed of football players. When compared, there is a significant difference in the effect of the hollow sprints method and the pickup / acceleration sprints method on the speed of football players. Therefore the authors conclude that speed training using the pickup / acceleration sprints method is more significant than the hollow sprints method seen from the $t$ test.

Keywords: hollow sprints, pickup/acceleration sprints, speed and training methods. 


\section{PENDAHULUAN}

Kondisi fisik merupakan suatu aspek yang penting dalam olahraga karena hal tersebut berpengaruh terhadap kualitas dan kemampuan atlet dalam suatu cabang olahraga. Jadi, kondisi fisik merupakan salah satu faktor yang sangat penting dalam performa atlet di lapangan, dan bahkan sebagai keperluan bagi atlet untuk meraih prestasi olahraga, sebab tanpa didukung dengan kondisi fisik yang bagus atlet tidak akan mampu untuk mencapai prestasi puncak.

Latihan itu sendiri merupakan aktifitas untuk meningkatkan keterampilan berolahraga dengan menggunakan berbagai peralatan sesuai dengan tujuan dan kebutuhan cabang olahraganya (Sukadiyanto, 2011). Latihan kondisi fisik merupakan aktivitas gerak jasmani yang dilakukan secara sistematik dan ditingkatkan secara progresif untuk mempertahankan atau meningkatkan derajat kebugaran jasmani agar tercapai kemampuan fisik yang optimal (Juliantine, 2007). Oleh karena itu latihan kondisi fisik perlu mendapat perhatian yang serius direncanakan dengan matang dan sistematis sehingga tingkat kesegaran jasmani dan kemampuan fungsional alat-alat tubuh lebih baik.

Salah satu aspek komponen fisik yang dominan dalam cabang olahraga adalah kecepatan. Hal ini dikarenakan, kecepatan mempunyai peranan yang sangat menentukan terhadap seorang atlet. Olahragawan yang memiliki kecepatan akan dengan mudah mendapatkan apa yang menjadi targetnya. Dengan keterampilan yang dimiliki, seorang atlet, ia seringkali dituntut agar dapat melakukan kemampuannya dengan optimal dan mampu menghadapi tekanan-tekanan yang terjadi dalam pertandingan atau perlombaan dengan cepat.

Penguasaan kecepatan memegang peranan penting dalam pembuatan program latihan, tujuannya adalah untuk meningkatkan kemampuan semua fungsional tubuh dalam meningkatkan prestasi. Kemampuan kecepatan ini juga akan berpengaruh terhadap penguasaan teknik-teknik gerakan yang akan dilatihkan.

Kecepatan (speed) sering digambarkan dengan waktu tempuh dengan satuan second, detik, menit dan jam. Kecepatan yang dimaksud adalah waktu yang dibutuhkan oleh seseorang untuk mencapai jarak tertentu. Kecepatan bukan hanya berarti untuk menggerakan seluruh tubuh dengan cepat akan tetapi dapat pula dengan menggerakan anggota tubuh dalam waktu yang sesingkatsingkatnya. Kecepatan bukan hanya berarti menggerakkan seluruh tubuh dengan cepat akan tetapi dapat pula 
dengan menggerakkan anggota tubuh dalam waktu cepat.

Komponen kecepatan merupakan salah satu faktor yang menentukan hasil yang dicapai. Kecepatan merupakan komponen fisik yang esensial pada beberapa cabang olahraga, seperti lari, bergerak, meraih atau merubah posisi secepat mungkin.

Dengan kata lain, kecepatan adalah menggerakkan seluruh tubuh dalam waktu yang singkat dan jarak yang pendek. Kecepatan adalah salah satu kemampuan biomotor penting yang dibutuhkan olahraga untuk melakukan perjalanan yang cepat atau bergerak cepat (Liebenson, 2009). Kecepatan ialah kemampuan untuk melakukan gerakangerakan yang sejenis secara berturutturut dalam waktu yang sesingkatsingkatnya, atau kemampuaan untuk menempuh suatu jarak dalam waktu yang cepat (Udam, 2017).

Kecepatan dapat ditingkatkan dengan berbagai macam metode latihan, dintaranya uphill (lari menaiki bukit/pegunungan), interval sprint (lari dengan mengatur jarak dengan diselingi waktu istirahat), repetition training (metode pengulangan dan jarak yang pendek), downhill (lari menuruni bukit/pegunungan), hollow sprints (kombinasi sprint dan jogging), pickup sprints (lari dengan penambahan kecepatan) dan lain sebagainya (Bompa, 2009).

\section{METODE}

Metode penelitian yang
digunakan dalam penelitian ini
menggunakan metode eksperimen. Metode ini digunakan untuk mengetahui hasil ketika sudah dilakukan treatment atau latihan tambahan. Penelitian eksperimen merupakan penelitian yang dimaksudkan untuk mnegetahui ada tidaknya akibat dari sesuatu yang dikenakkan pada subjek selidik (Arikunto, 2006).

Dalam penelitian ini, dibutuhkan sekumpulan orang untuk ikut terlibat di dalamnya. Dimana mereka berasal dari suatu populasi dalam suatu wilayah atau lingkungan dengan keragamannya. Populasi adalah keseluruhan subjek penelitian. Berdasarkan penelitian tersebut, maka populasi merupakan keseluruhan elemen yang ada dalam penelitian yang akan dilakukan. Populasi adalah wilayah generalisasi yang terdiri atas:objek/subyek yang mempunyai kualitas dan karakteristik tertentu yang ditetapkan oleh peneliti untuk dipelajari dan kemudian ditarik kesimpulannya (Sugiyono, 2017). Maka ditetapkan populasi dalam penelitian ini adalah siswa KU-19 Sekolah Sepak Bola Pamong Praja Kabupaten. Garut sebanyak 20 orang. 
Dari sekian banyak populasi yang ada, akan diambil beberapa orang untuk dijadikan sampel penelitian. Sampel merupakan sebagian atau bertindak sebagai perwakilan dari populasi sehingga hasil penelitian yang berhasil diperoleh dari sampel dapat digeneralisasikan pada populasi (Hidayat, 2012). Tentang teknik sampling yang digunakan dalam penelitian ini adalah teknik sampling jenuh. Sampling jenuh adalah teknik penentuan sampel bila semua anggota populasi digunakan sebagai sampel. Hal ini sering dilakukan bila jumlah populasi relatif kecil, kurang dari 30 orang, atau penelitian yang ingin membuat generalisasi dengan kesalahan yang sangat kecil. Dimana semua anggota populasi dijadikan sampel (Sugiyono, 2017). Adapun sampel dalam penelitian ini berjumlah 20 orang.

Instrumen merupakan suatu alat yang digunakan untuk penelitian. Ada banyak instrumen yang digunakan dalam suatu penelitian, dalam penelitian ini penulis menggunakan instrument dengan metode tes. Tes adalah serentetan pertanyaan atau latihan serta alat lain yang digunakan untuk mengukur keterampilan, pengetahuan intelegensi, kemampuan atau bakat yang dimiliki oleh individu atau kelompok (Arikunto, 2006)
Guna untuk tercapainya keberhasilan dalam penelitian maka diperlukan alat ukur untuk mendapatkan data. Pengukuran berguna dalam proses pengumpulan data/informasi dari suatu obyek tertentu, dalam proses pengukuran diperlukan suatu alat ukur (Nurhasan dan Cholil, 2007). Untuk kecepatan umumnya diukur dengan lari menempuh jarak pendek. Berdasarkan pendapat tersebut, maka melalui pengukuran peneliti dapat mengumpulkan data secara objektif yang diperlukan dalam penelitian ini, yaitu berupa angka-angka yang dapat diolah secara statistik. Tujuannya agar dapat mengetahui pengaruh dari hasil perlakuan dan perbedaannya yang merupakan tujuan akhir dari eksperimen, khususnya dalam mengukur aspek kecepatan dengan alat ukur kecepatan $30 \mathrm{~m}$.

\section{HASIL DAN PEMBAHASAN}

Data yang diperoleh dari hasil penelitian merupakan hasil data-data mentah, sehingga data-data tersebut harus diolah dan dianalisis secara statistika. Data-data yang terdapat dalam penelitian ini diolah dan dianalisis berdasarkan langkah-langkah penelitian yang telah dikemukakan.

\footnotetext{
Diagram 1

Grafik Perbandingan Tes Awal dan

Akhir

Metode Hollow Sprints (dalam detik)
} 


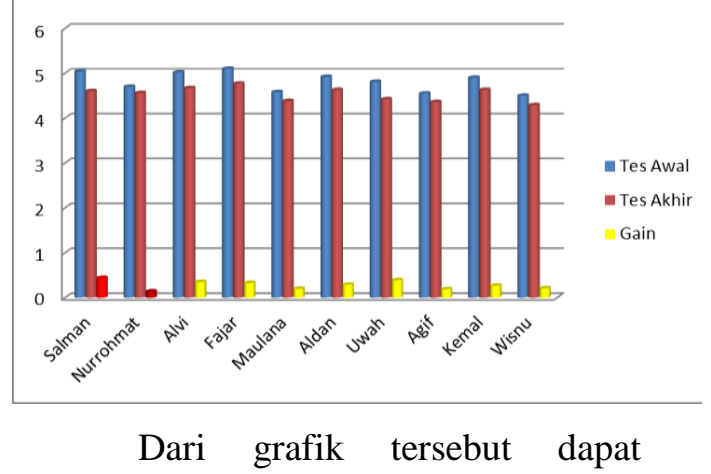

diketahui bahwa peningkatan kecepatan yang besar diperoleh oleh sampel bernama Salman dengan selisih 0.44 dari tes awal. Kemudian peningkatan yang kurang besar diperoleh oleh sampel yang bernama Nurrohmat dengan selisih 0.14 dengan tes awal. Dapat diketahui bahwa peningkatan dari tes awal dan tes akhir untuk metode Hollow Sprint sebesar 0.281. Adapun presentase jumlah nilai rata-rata dari tes awal sebesar $50 \%$ dan tes akhir sebesar $47 \%$. Dengan presentase selisih peningkatan tes awal dan tes akhir sebesar 3\%.

\section{Diagram 2}

\section{Grafik Perbandingan Tes Awal dan} Akhir Metode Pickup/Acceleration Sprints (dalam detik)

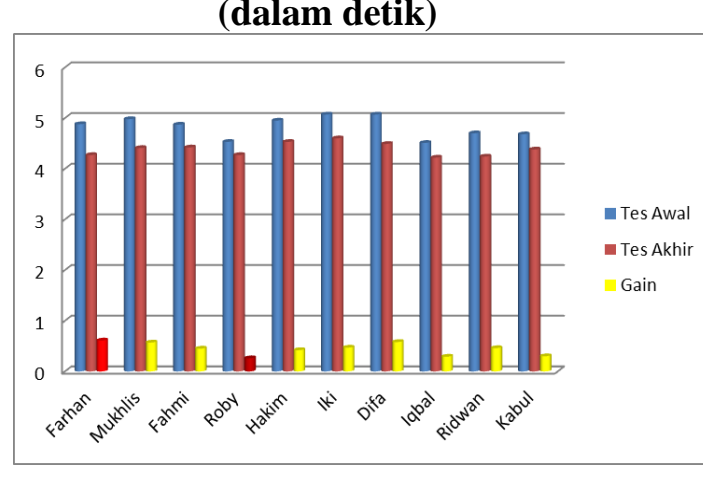

Dari grafik tersebut dapat diketahui bahwa peningkatan kecepatan yang besar diperoleh oleh sampel bernama Farhan dengan selisih 0.61 dari tes awal. Kemudian peningkatan yang kurang besar diperoleh oleh sampel yang bernama Roby dengan selisih 0.26 dengan tes awal. Dengan hasil peningkatan dari tes awal dan tes akhir sebesar 0.441. Adapun presentase jumlah nilai rata-rata dari tes awal sebesar 50\% dan tes akhir sebesar 45\%. Dengan presentase selisih peningkatan tes awal dan tes akhir sebesar 5\%.

Dalam pelaksanaannya di lapangan, semua sampel belum bisa beradaptasi dengan cepat sampai pertemuan ke-3. Peningakatan adaptasi dan pemeberian intruksi dari peneliti terlihat pada pertemuan ke-4. Dengan beradaptasinya semua sampel dengan diberikannya variasi latihan tambahan, membuat semua sampel melakukan dengan penuh semangat dan selalu memperhatikan intruksi yang diberikan oleh peneliti. Terjadinya rasa semangat yang tinggi memberikan pengaruh peningkatan kecepatan pada pertengahan pertemuan, tepatnya pertemuan ke-15 dan yang terlihat oleh peneliti bahwa kelompok metode pickup/acceleration sprints lebih cepat dalam berdaptasi dan intruksi dari peneliti dapat dipahami dengan benar. Dan program latihan ini juga diberikan sampai dilakukannya post test (tes akhir) dengan hasil yang cukup baik dalam peningkatan kecepatan 
dengan dibandingkan dari pre test (tes awal). Disamping itu, ada beberapa sampel yang kemampuan kecepatannya sukar akan ditingkatkan karena mempunyai kelebihan dalam komponen daya tahan.

Dalam pelaksanaanya kedua latihan ini sangat praktis. Latihan ini bisa dilakukan di tempat yang tidak terlalu luas dan tanpa mengeluarkan biaya yang besar. Alat yang dipakai dalam latihan tidak terlalu sulit dan bisa menggunakan alat yang ada sebagai pengatur batas atau tanda, contohnya tali, kayu,sandal dan banyak yang lainnya.

Disamping metode latihan yang praktis, kedua latihan ini cenderung banyak menggunakan energi. Dalam pelaksanaannya kedua latihan ini dilakukan secara maksimal dan fase pemulihan dalam gerakannya. Adapun gerakannya ini ada fase jogging yang bisa dimanfaatkan untuk melakukan gerakan yang maksimal. Misalnya Hollow Sprints ini merupakan metode latihan campuran intensitas tinggi dan rendah. Hollow sprints merupakan metode latihan yang terdiri dari 2 sprint yang diselingi dengan suatu periode kosong (hollow) dan fase kosong ini bisa jogging atau jalan (Fajri et al., 2019). Dengan sistem kerja tersebut, bisa dikatakan model latihan yang berselang. Cara melatih metode ini, misalnya : sprint $10 \mathrm{~m}$ - jogging $10 \mathrm{~m}$ sprint $10 \mathrm{~m}$. Untuk mengetahui lebih jelas pelaksanaan metode latihan ini, dapat dilihat pada gambar berikut.

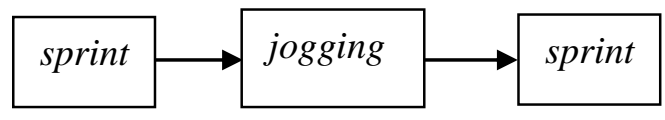

\section{Gambar 1}

Pengaturan Kecepatan Lari, Jogging/Jalan

Kemudian, pickup sprints yaitu dimulai dari pelan, ditingkatkan kecepatannya, sampai dengan kecepatan penuh (Mylsidayu, 2015). Adapun cara melatihnya, misalnya : jogging (lari santai) $10 \mathrm{~m}$-lebih cepat $10 \mathrm{~m}$-sprint cepat $10 \mathrm{~m}$ sampai maksimal.

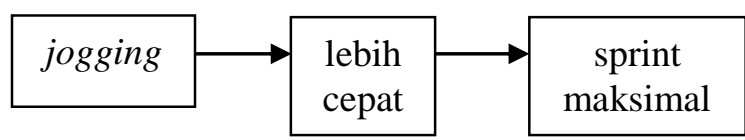

\section{Gambar 2 Penambahan Kecepatan}

Dalam setiap latihan yang dilakukan dengan sistematis dan aturan latihan yang ada, latihan kecepatanpun akan mempengaruhi terhadap kekuatan otot. Latihan yang efektif dan efesien serta berkualitas ialah latihan yang memperhatikan terhadap norma-norma latihan atau komponen latihan (Bompa, 2009).

Untuk pencapaian yang optimal, latihan kecepatan ini harus dilakukan secara terus-menerus sesuai aturan latihan. Disamping itu, perlu diperhatikan faktor-faktor yang 
mempengaruhi dalam melakukan latihan kecepatan diantaranya, sistem energi dan sistem neuromuskuler (Lubis, 2013).

Tabel 1

Karakteristik Sistem Energi

\begin{tabular}{|lll|}
\hline \multicolumn{1}{|c}{$\begin{array}{c}\text { Sistem } \\
\text { ATP-PC }\end{array}$} & \multicolumn{1}{c|}{$\begin{array}{c}\text { Sistem } \\
\text { Asam } \\
\text { Laktat }\end{array}$} & \multicolumn{1}{c|}{$\begin{array}{c}\text { Sistem } \\
\text { Oksigen }\end{array}$} \\
\hline Anaerobik & Anaerobik & Aerobik \\
\hline Sangat cepat & Cepat & Lambat \\
\hline PC & Glikogen & Glikogen \\
\hline $\begin{array}{l}\text { ATP sangat } \\
\text { terbatas }\end{array}$ & ATP & ATP \\
& terbatas & tidak \\
aktifitas & aktifitas & daya \\
yang & dengan & tahan \\
cepat,power, & durasi 1-3 & \\
aktifitas & menit & \\
pendek & & \\
\hline
\end{tabular}

Sumber : (Kayan Agus Widia 2011, http://eprints.uns.ac.id/6105/)

Proses pelaksanaan bentuk latihan kecepatan pada umumnya menggunakan sistem energi an-aerob (tanpa oksigen), atau yang lebih dikenal dengan istilah ATP (Adenosina Trifospfat) -PC (Phosphocreatine). Kecenderungan penggunaan ATP (Adenosina Trifospfat) -PC (Phosphocreatine) ini lebih disebabkan oleh jarak yang ditempuh tergolong pendek yang secara otomatis waktu yang digunakan pun singkat, yaitu sekitar 6 sampai dengan 10 detik untuk setiap kali latihan.
Istirahat dalam melatih kecepatan harus diberikan cukup lama dan bervariasi diantara pengulangan sampai denyut nadi awal, ini dikarenakan yang lelah bukan hanya otot, tetapi sistem persyarafan dan memperhatikan sumber energi dan pembentukan kembali sumber energi tersebut. Sumber energi pada latihan kecepatan adalah sistem energi anaerobik alaktasik ( $C P$ system) yang berlangsung 2-8 detik. Dalam melakukan kecepatan harus dilakukan secara maksimal dengan intensitas $100 \%$ kemampuaannya. Perlu diperhatikan bahwa intensitas merupakan besar kecilnya usaha yang dilakukan dalam melakukan latihan. Untuk lebih jelas mengenai intensitas dalam kecepatan, bisa dilihat pada tabel sebagai berikut.

Tabel 2

Intensitas Olahraga Kecepatan dan Kekuatan

\begin{tabular}{|ccc|}
\hline $\begin{array}{l}\text { Nomor } \\
\text { Intensitas }\end{array}$ & $\begin{array}{c}\text { Presentase } \\
\text { Kemampuan }\end{array}$ & Intensitas \\
\hline $\mathbf{1}$ & $30-50$ & Rendah \\
\hline $\mathbf{2}$ & $50-70$ & Intermedit \\
\hline $\mathbf{3}$ & $70-80$ & Medium \\
\hline $\mathbf{4}$ & $80-90$ & $\begin{array}{c}\text { Sub- } \\
\text { Maksimal }\end{array}$ \\
& & Maksimal \\
\hline $\mathbf{5}$ & $90-100$ & Super \\
$\mathbf{6}$ & $100-105$ & Maksimal \\
& &
\end{tabular}

Sumber : (Satriya, 2011) 
Jenis latihan bisa disesuaikan dengan gerakan yang spesifik di cabang olahraga masing-masing, intensitas latihan harus sesuai dengan apa yang telah dikemukakan pada tabel tersebut, sehingga tidak menggeser tujuan latihan kecepatan. Karena bergesernya penggunaan sistem energi yang dipakai saat bekerja bisa menjadikan tujuan latihan tidak tercapai.

Jarak tempuh dalam melakukan latihan tidak boleh lebih dari $60 \mathrm{~m}$ serta waktu tempuhpun tidak lebih dari 8 detik, ini dikarenakan yang menjadi tujuan latihan adalah melatih kecepatan bukan melatih daya tahan kecepatan. Kemudian melatih kecepatan dilakukan secara berulang-ulang dengan pengulangan yang banyak dan usaha yang maksimal sesuai kebutuhan cabang olahraga. Perlu diperhatikan juga bahwa faktor kecepatan dipengaruhi oleh keturunan, waktu rekasi, elastisitas otot, teknik kecepatan, kemampuan beban pemberat, jenis otot dan juga konsentrasi (Emral, 2018).

Populasi adalah keseluruhan dari kumpulan elemen yang memiliki sejumlah karakteristik umum, yang terdiri dari bidang-bidang yang akan diteliti (Amirullah, 2015). Populasi dalam penelitian ini adalah siswa KU-19 SSB Pamong Praja Kabupaten. Garut sebanyak 20 orang. Peneliti menggunakan populasi dari SSB Pamong
Praja Kabupaten Garut karena peneliti terlibat dalam kepengurusan dan sebagai pelatih SSB Pamong Praja Kabupaten Garut, selain itu guna mengefektifkan waktu peneliti, serta lebih meningkatkan mutu latihan sepak bola yang ada di Kabupaten Garut. Disamping itu peneliti ingin meneliti kondisi fisik kecepatan pada pemain siswa KU-19 SSB Pamong Praja Kabupaten Garut dengan selalu berprestasi dalam kompetisi intern Persigar.

Seluruh jumlah (20 orang pemain sepak bola) digunakan sebagai sampel. Maka dari itu, 20 siswa KU-19 SSB Pamong Praja Kabupaten Garut dijadikan sampel penelitian. Untuk menentukan latihan, dilakukan terlebih dahulu tes awal dengan tes lari cepat $30 \mathrm{~m}$. Setelah tes didapat, kemudian dilakukan penyusunan ranking dari yang terbesar sampai terkecil dan penjodohan dengan menggunakan metode A-B-B-A, metode ini digunakan agar kedua kelompok mempunyai kemampuan yang seimbang (equivalen). Kemudian sampel dipisahkan menjadi dua kelompok yaitu kelompok metode hollow sprints berjumlah 10 orang dan kelompok pickup/acceleration sprints berjumlah 10 orang. Adapun hasil data yang diperoleh, sebagai berikut.

Tabel. 3

Hasil Tes Data Awal dan Akhir Kelompok Hollow Sprints 


\begin{tabular}{|clccc|}
\hline NO & Nama & $\begin{array}{c}\text { Tes } \\
\text { Awal }\end{array}$ & $\begin{array}{c}\text { Tes } \\
\text { Akhir }\end{array}$ & Selisih \\
\hline $\mathbf{1}$ & Salman & 5,04 & 4,60 & 0,44 \\
\hline $\mathbf{2}$ & Nurrohmat & 4,70 & 4,56 & 0,14 \\
\hline $\mathbf{3}$ & Alvi & 5,02 & 4,67 & 0,35 \\
\hline $\mathbf{4}$ & Fajar & 5,10 & 4,77 & 0,33 \\
\hline $\mathbf{5}$ & Maulana & 4,58 & 4,38 & 0,20 \\
\hline $\mathbf{6}$ & Aldan & 4,92 & 4,63 & 0,29 \\
\hline $\mathbf{7}$ & Uwah & 4,81 & 4,42 & 0,39 \\
\hline $\mathbf{8}$ & Agif & 4,55 & 4,36 & 0,19 \\
\hline $\mathbf{9}$ & Kemal & 4,90 & 4,63 & 0,27 \\
\hline $\mathbf{1 0}$ & Wisnu & 4,50 & 4,29 & 0,21 \\
\hline $\mathbf{\Sigma}$ & Jumlah & 48,12 & 45,31 & 2,81 \\
\hline$\overline{\boldsymbol{X}}$ & Rata-rata & 4,812 & 4,531 & 0,281 \\
\hline
\end{tabular}

akhir sebesar 0.441. Adapun presentase jumlah nilai rata-rata dari tes awal sebesar $50 \%$ dan tes akhir sebesar $45 \%$. Dengan presentase selisih peningkatan tes awal dan tes akhir sebesar 5\%.

Hasil penelitian yang relevan sebelumnya yang sesuai dengan penelitian ini adalah yang dilakukan oleh Abara dengan mengambil judul

\section{Dapat diketahui bahwa} peningkatan dari tes awal dan tes akhir sebesar 0.281. Adapun presentase jumlah nilai rata-rata dari tes awal sebesar $50 \%$ dan tes akhir sebesar $47 \%$. Dengan presentase selisih peningkatan tes awal dan tes akhir sebesar 3\%.

Tabel. 4

Hasil Tes Data Awal dan

Akhir Kelompok Pickup/Acceleration Sprints

\begin{tabular}{|c|c|c|c|c|c|}
\hline No & Nama & $\begin{array}{c}\text { Tes } \\
\text { Awal }\end{array}$ & $\begin{array}{l}\text { Tes } \\
\text { Akhir }\end{array}$ & Selisih & peningkatan lari 100 meter anatara \\
\hline 1 & Farhan & 4,88 & 4,27 & 0,61 & kekuatan otot tungkai tinggi \\
\hline 2 & Mukhlis & 4,98 & 4,41 & 0,57 & dan rendah, dan juga pengaruh interaki \\
\hline 3 & Fahmi & 4,87 & 4,42 & 0,45 & denoan kekuatan \\
\hline 4 & Roby & 4,53 & 4,27 & 0,26 & an KeKuatan \\
\hline 5 & Hakim & 4,95 & 4,53 & 0,42 & otot tungkai terhadap peningkatan lari \\
\hline 6 & Iki & 5,07 & 4,60 & 0,47 & 100 meter. Dari hasil penelitian tersebut \\
\hline 7 & Difa & 5,07 & 4,49 & 0,58 & \\
\hline 8 & Iqbal & 4,51 & 4,22 & 0,29 & diperoleh peningkatan kecepatan lari \\
\hline 9 & Ridwan & 4,70 & 4,24 & 0,46 & untuk lari 100 meter adalah \\
\hline 10 & Kabul & 4,68 & 4,38 & 0,30 & \\
\hline$\Sigma$ & Jumlah & 48,24 & 43,83 & 4,41 & on \\
\hline$\overline{\bar{X}}$ & Rata-rata & 4,824 & 4,383 & 0,441 & ignifikan dibandingkan hollow sprints \\
\hline
\end{tabular}

Dapat diketahui bahwa peningkatan dari tes awal dan tes dan repitition sprints.

Persamaan penelitian ini dengan peneltian yang telah peneliti lakukan 
adalah tentang metode penelitian kecepatan lari antara metode hollow sprints dan pickup/accelartion sprints dalam peningkatan kecepatan lari. Metode yang digunakan dalam penelitian sama-sama menggunakan metode eksperimen.

\section{KESIMPULAN}

Berdasarkan pengolahan data dan analisis data dari latihan hollow sprints dan pickup/acceleration sprints terhadap peningkatan kecepatan pemain sepakbola SSB Pamong Praja Kabupaten Garut, maka penulis menyimpulkan bahwa: Latihan hollow sprints memberikan peningkatan yang signifikan terhadap peningkatan kecepatan. Latihan pickup/acceleration sprints memberikan peningkatan yang signifikan terhadap peningkatan kecepatan. Terdapat perbedaan peningkatan yang signifikan metode latihan hollow sprints dan pickup/acceleration sprints terhadap peningkatan kecepatan. Dimana latihan pickup/acceleration sprints memberikan peningkatan yang signifikan terhadap peningkatan kecepatan dibandingkan hollow sprints.

Dari diskusi penemuan di atas maka peneliti dapat memberikan gambaran kepada pelatih sepak bola khususnya di SSB Pamong Praja Kabupaten Garut bahwa dengan metode latihan pickup/acceleration ini akan memberikan peningkatan yang signifikan terhadap kecepatan, dibandingkan dengan mengunakan metode latihan hollow sprints. Diharapakan untuk penelitian selanjutnya disarankan menjadi acuan atau patokan dapat meneliti denga jumlah sampel yang lebih banyak, usia sampel yang sudah menginjak remaja, dan subjek penelitian mencakup sekolah sepakbola yang lebih berkompeten dalam mencetak atlet professional. Diharapkan untuk pembaca dapat dijadikan rekomendasi atau acuan dalam proses pelatihan mengenai metode latihan meningkatkan kecepatan.

\section{DAFTAR PUSTAKA}

Abara \& UNS. 2011. Perbandingan Pengaruh Metode Latihan Acceleration Sprints, Hollow Sprints, dan Repipition Sprints Terhadap Peningkatan Prestasi Lari 100 meter.

Amirullah. 2015. Populasi dan Sampel (Pemahaman, Jenis dan Teknik). Metode Penelitian Manajemen. https://doi.org/10.1007/BF0035315 7.

Arikunto, S. 2006. Prosedur Penelitian Suatu Tindakan Praktik. Jakarta: Rineka Cipta.

Emaral. 2018. Pengantar Teori dan Metodologi Peatihan Fisik. Depok: KENCANA.

Fajri, et.al. 2019. Pengaruh Latihan Hollow Sprints Terhadap Kecepatan Atlet Bintang Timur Football Club. Jurnal Stamina.

Hidayat, A. 2012. Populasi dan sampel. Metode Penelitian Kuantitatif, Kualitatif Dan R\&D.

Liebenson, C. 2009. Training for speed. Journal of Bodywork and Movement Therapies. https://doi.org/10.1016/j.jbmt.2009 
.07 .001 .

Lubis, Johansyah. 2013. Panduan Praktis Penyusunan Program Latihan. Jakarta: PT. Raja Grafindo Perkas. Juliantine, et.al. 2007. Teori Latihan. Bandung: Universitas Pendidikan Indonesia.

Mylsidayu, A., \& Kurniawan, F. 2015. Ilmu Kepelatihan Dasar. Bandung: Alfabeta.

Nurhasan dan Cholil. 2007. Tes dan Pengukuran Keolahragaan. Bandung Jurusan Pendidikan Kepelatihan FPOK UPI.

Satriya. 2011. Pembinaan Kondisi Fisik. Joint Conference UPI-UITM 2011 "Strengthening Research Collaboration on Education.

Sugiyono. 2017. Metode Kuantitatif. In Metode Penelitian Kuantitatif, Kualitatif, dan R\&D.

Sukadiyanto, dkk. 2011. Pengantar Teori dan Melatih Fisik. Bandung: Lubuk Agung.

Tudor, Bompa. 2009. Theory and Methodology Of Training. Lowa: Kendal Publishing Company.

Udam, M. 2017. Pengaruh Latihan Shuttle-run dan Zig-zag-run Terhadap Kemampuan Dribbling Bola Pada Sekolah Sepak Bola (SSB) Imanuel Usia 13-15 Tahun. Jurnal Pendidikan Jasmani, Olahraga dan Kesehatan.

Widia, D. BAB II [Online] Tersedia: http://eprints.uns.ac.id/6105/ 